\title{
Improved efficiency of bovine cloning by autologous somatic cell nuclear transfer
}

\author{
Xiao-yu Yang, Hua Li, Qing-wen Ma, Jing-bin Yan, Jiang-guo Zhao, Hua-wei Li, Hai-qing Shen, \\ Hai-feng Liu, Ying Huang, Shu-Zhen Huang, Yi-Tao Zeng and Fanyi Zeng \\ Shanghai Institute of Medical Genetics, Shanghai Children's Hospital, Shanghai Jiao Tong University, 24/1400 West \\ Beijing Road, Shanghai 200040, People's Republic of China
}

Correspondence should be addressed to F Zeng; Email: fyzeng@simg.org or ytzeng@stn.sh.cn

\begin{abstract}
Somatic cell nuclear transfer (SCNT) has been used for the cloning of various mammals. However, the rates of successful, healthy birth are generally poor. To improve cloning efficiency, we report the utilization of an 'autologous SCNT' cloning technique in which the somatic nucleus of a female bovine donor is transferred to its own enucleated oocyte recovered by ovum pick up, in contrast to the routine 'allogeneic SCNT' procedure using oocytes from unrelated females. Our results showed that embryos derived from autologous SCNT have significantly higher developmental competence than those derived from allogeneic SCNT, especially at the eight-cell (60 vs $44 \%$ ), morula (45 vs $36 \%$ ), and blastocyst (38 vs $23 \%$ ) stages. The pregnancy and birth rates were also higher for the autologous (39 and $23 \%$ ), compared to the allogeneic (22 and $6 \%$ ) SCNT groups. Genome-wide histone3-lysine9 methylation profiles reveal that autologous SCNT embryos have less epigenetic defects than the allogeneic SCNT embryos. This study indicates that autologous SCNT can improve the efficiency of bovine cloning with less reprogramming deficiency.

Reproduction (2006) 132 733-739
\end{abstract}

\section{Introduction}

Somatic cell nuclear transfer (SCNT) has been successfully utilized in generating cloned animals in various mammalian species, such as sheep, cattle, mouse, goat, pig, cat, rabbit, rat, mule, and horse (Campbell et al. 1996, Wilmut et al. 1997, Cibelli et al. 1998, Kato et al. 1998, Wakayama et al. 1998, 1999, Baguisi et al. 1999, Polejaeva et al. 2000, Chesne et al. 2002, Shin et al. 2002, Galli et al. 2003, Woods et al. 2003, Zhou et al. 2003). At present, the SCNT technique involves the adoptive transfer of a donor somatic nucleus to another individual's enucleated oocyte, termed here as 'allogeneic SCNT'. The overall efficiency of this procedure is low (Wilmut et al. 2002). Cloned embryos often die soon after implantation (Rideout et al. 2001) and throughout gestation, with many fetuses displaying a neonatal phenotype resembling large offspring syndrome (Hiendleder et al. 2004) with respiratory and metabolic abnormalities, as well as dysfunctional placentas (Wakayama \& Yanagimachi 1999). The basis of this low efficiency remains unclear. Incomplete epigenetic reprogramming of the somatic nucleus was proposed to cause developmental failure of cloned embryos (Rideout et al. 2001), and the interaction between the nucleus of the donor cell and the cytoplasm of the recipient oocyte was also suggested to play an important role in somatic nuclear reprogramming during the early development of the cloned embryos (Hiendleder et al. 2004).

In order to increase cloning efficiency, improve the developmental potential of cloned embryos, and reduce the incidence of prenatal and postnatal abnormalities, we modified the SCNT procedure by transferring a female bovine donor cell nucleus to the donor's own enucleated oocyte, a process we term 'autologous SCNT'. Here, we compared the efficiency of bovine cloning using autologous SCNT with allogeneic SCNT at various development stages (preimplantation, postimplantation, and after birth). We also analyzed the genome-wide histone3-lysine9 methylation (H3-dimethK9) profiles of the in vitro autologous SCNT and allogeneic SCNT blastocysts. Our results show that the autologous SCNT can improve the efficiency of bovine cloning and result in less abnormal epigenetic profiles.

\section{Materials and Methods}

Unless specifically indicated, all chemicals were bought from Sigma. 


\section{Animals}

Dairy heifers (Holstein) between 12 and 13 months of age at the beginning of the research with a similar weight and health condition were used for ovum pick up (OPU). The heifers were barn-housed and fed a mixed ration consisting of hay and a commercial feed concentrate. Heifers were provided by the Songjiang Experimental Animal Facility affiliated with the Institute of Medical Genetics of Shanghai Jiao Tong University, China. The investigations were conducted in accordance with the protocols and guidelines for agricultural animal research imposed by the Committee for Ethics of Shanghai.

\section{Ovum pick up and in vitro maturation}

The OPU was performed weekly as we described previously (Yang et al. 2005a) using ultrasound guidance (SSD-500; Aloka Co. Tokyo). Briefly, after emptying the rectum and thoroughly cleaning the vulva and perineal area, the transducer was advanced to the external os of the cervix. When the ovary was relocated and the targeted follicles were stabilized on the puncture line, an 18-gauge needle was inserted in the guide, advanced through the vaginal wall and into the follicle antrum. Follicles $(2-5 \mathrm{~mm}$ in diameter) together with the follicular fluid were aspirated using continuous negative pressure (about $80 \mathrm{mmHg}$ ) into D-PBS (pH 7.4; Gibco) medium containing 3\% BSA and $2 \mathrm{IU} / \mathrm{ml}$ heparin.

In vitro maturation of bovine oocytes was carried out as described previously (Huang et al. 2001). Only cumulus oocyte complexes (COCs) with a compact, nonatretic, multilayer cumulus oophorus corona radiata, and homogenous ooplasm were selected for maturation. The selected COCs were matured in tissue culture medium (TCM)-199 (Gibco) with 10\% fetal bovine serum (FBS) (Hyclone, Logan, UT, USA), $10 \mu \mathrm{g} / \mathrm{ml}$ luteinizing hormone, $1 \mu \mathrm{g} / \mathrm{ml} \mathrm{E} 2$ and $1 \mu \mathrm{g} / \mathrm{ml}$ follicle-stimulating hormone, and 1\% (V:V) penicillin/streptomycin in $50 \mu \mathrm{l}$ microdrops with mineral oil. Maturation was performed at $38.5^{\circ} \mathrm{C}$ in a humidified $5 \% \mathrm{CO}_{2}$ in air incubator.

\section{Donor cell preparation}

On the day of NT, $20 \mathrm{~h}$ after the onset of maturation, cumulus cells were isolated by pipetting in PBS, supplemented with $2.5 \mathrm{mg} / \mathrm{ml}$ hyaluronidase and transferred to TCM-199 for use as donor cells. They were fused with enucleated oocytes either from the same donor female (autologous cloning) or from a different female (allogeneic cloning).

\section{Nuclear transfer and embryo culture}

All matured oocytes having an extruded first polar body with uniform cytoplasm were used for nuclear transfer. Nuclear transfer was performed as previously described
(Park et al. 2004, Yang et al. 2005b) with minor modifications. Briefly, after $20 \mathrm{~h}$ of in vitro maturation, oocytes were transferred into microdrops of TCM-199 supplemented with $5 \mu \mathrm{g} / \mathrm{ml}$ cytochalasin B and $10 \%$ FCS. Enucleation was performed with a $20 \mu \mathrm{m}$ (internal diameter) glass pipette by aspirating the first polar body and a small amount of surrounding cytoplasm. The expelled cytoplasm, but not the enucleated oocyte per se, was stained with $1 \mu \mathrm{g} /$ $\mathrm{ml} \mathrm{Hoechst} 33342$ (to confirm that the nuclear material had been removed). After enucleation, the donor cell was introduced through the same slit in the zona pellucida and wedged between the zona pellucida and the cytoplasm membrane, to facilitate close membrane contact for subsequent fusion. After injection, reconstructed embryos were placed in TCM-199 with 10\% FCS until fusion.

Reconstructed oocytes were electrically fused $22 \mathrm{~h}$ after initiation of maturation (hpm) in a buffer composed of $0.3 \mathrm{M}$ mannitol, $0.15 \mathrm{mM}$ calcium, and $0.15 \mathrm{mM}$ magnesium. Fusion was performed at room temperature in a chamber (filled with fusion buffer) with two stainless steel electrodes, $1 \mathrm{~mm}$ apart. Cell fusion was induced with two pulses of direct current $(2.5 \mathrm{kV} / \mathrm{cm}$ for $10 \mu \mathrm{s}$ each) by a BTX Electro Cell Manipulator 200 (BTX, San Diego, CA, USA). Embryos were examined for fusion under a microscope. All fused embryos were further activated by culturing for an additional $5 \mathrm{~h}$ in TCM-199 medium with $10 \%$ FCS, $5 \mu \mathrm{g} / \mathrm{ml}$ cytochalasin B, and $10 \mu \mathrm{g} / \mathrm{ml}$ cycloheximide.

Reconstructed embryos were cultured in microdrops of B2 medium (INRA, Paris, France) with $10 \%$ FCS on a monolayer of Vero cells (Yang et al. 2005b), under a humidified atmosphere of $5 \% \mathrm{CO}_{2}$ in air at $38.5{ }^{\circ} \mathrm{C}$. The cleavage and the blastocyst rates were determined at $48 \mathrm{~h}$ and 7 days after activation respectively.

\section{In vitro fertilization (IVF)}

As a control, $20 \mathrm{~h}$ after in vitro maturation, metaphase II (MII) oocytes were fertilized with frozen-thawed bull semen from a single ejaculate (Dinnyes et al. 2000). The embryos were then cultured as described previously.

\section{Embryo transfer}

On the seventh day after observed estrus, 13 singleautologous SCNT and 18 single-allogeneic SCNT embryos were transferred nonsurgically into the uterine lumen ipsilateral to the corpus luteum of each heifer (Chinese Holstein Cattle). Pregnancies were confirmed on day 60 by ultrasonography and thereafter on day 90 by trans-rectal palpation. These cows were observed periodically until the cloned calves were born.

\section{Microsatellite determination of cloned calves}

Genomic DNA was extracted from peripheral blood of the cloned calves, donor heifers and foster mothers, 
randomly selected Chinese Holstein Cattle, as well as donor cell lines for microsatellite genotyping of parentage identification. Nine microsatellite markers recommended by the International Society of Animal Genetics (ISAG) in Tours, France, 1996 - BM1824, BM2113, SPS115, ETH3, ETH10, ETH225, TGLA122, TGLA126, TGLA227 - were chosen for analysis of parentage testing (three multiplexes) (http://www.projects.roslin.ac.uk/cdiv/markers.html) at Genecore Biotechnologies, Shanghai, China.

\section{Amplification and sequencing of mtDNA D-loop}

DNA was extracted from peripheral blood of donor heifers, foster mothers, and cloned calves. The complete D-loop, a mitochondrial DNA (mtDNA) mutation hot spot, was amplified with primer pairs $\mathrm{H} 1$ (5'-CTGCAGTCTCACCATCAACC-3') and L1 (5'-GTGTAGATGCTTGCATGTGTAAGT-3'). PCRs were performed as follows: a pre-denaturation step of $94^{\circ} \mathrm{C}$ for $5 \mathrm{~min}$ followed by 32 cycles of $94{ }^{\circ} \mathrm{C}$ for $45 \mathrm{~s}, 62{ }^{\circ} \mathrm{C}$ for $45 \mathrm{~s}$ and $72{ }^{\circ} \mathrm{C}$ for $1 \mathrm{~min}$, and a final extension step at $72{ }^{\circ} \mathrm{C}$ for $10 \mathrm{~min}$. PCR products were detected on a $2 \%$ agarose gel and purified with UltraPareTM PCR purification Kit (SBS Genetech, Beijing, China) according to the manufacturer's instructions. Direct sequencing of PCR products was performed on an ABI377 DNA sequencer, and sequence homology analyzed with Cluster $X$ software.

\section{Indirect immunoflurorescence of histone $\mathrm{H3}-\mathrm{Kg}$}

Procedures using an antibody to identify H3-K9 dimethylation specifically in the context of constitutive heterochromatin in the embryo were performed as described by Santos et al. (2003) with minor modifications. Briefly, blastocysts were washed in PBS, fixed for 15 min in PBS with 4\% paraformaldehyde, and permeabilized with $0.5 \%$ Triton X-100 in PBS for 30 min at room temperature (RT). After washing with $0.05 \%$ Tween-20 in PBS, samples were blocked overnight at $4{ }^{\circ} \mathrm{C}$ in blocking solution (1\% BSA and $0.05 \%$ Tween-20 in PBS). The preimplantation embryos were stained overnight at $4{ }^{\circ} \mathrm{C}$ with anti-histone $\mathrm{H} 3$-dimethK9 antibody (Abcam, UK) diluted in the ratio of 1:250, followed by goat anti-rabbit
FITC-conjugated secondary antibody detection. Observations were performed with a Nikon TE2000 epifluorescence microscope. Embryos that could establish histone H3-dimethK9 asymmetry, with lightly stained trophectoderm and more intensely stained inner cell mass (ICM) uniformly, were considered normal, whereas those embryos with a homogeneous staining pattern were classified as having abnormal $\mathrm{H} 3-\mathrm{K} 9$ staining (Dean et al. 2001, Santos et al. 2003).

\section{Statistical analysis}

Differences in developmental potentials among different treatment groups were analyzed with chi-squared tests using SAS 6.12 program. A $P$ value $<0.05$ was considered significant.

\section{Results \\ Ovum pick up}

The average number of oocytes recovered per heifer was 8.2 COCs. A total of 4044 COCs were obtained from 492 OPU procedures, and 1973 high-quality MII oocytes from this group were used for SCNT and 306 for IVF.

\section{Comparison of preimplantation and postimplantation development between embryos from autologous SCNT and allogeneic SCNT}

As summarized in Table 1, the autologous SCNT embryos had significantly higher developmental potential than the allogeneic SCNT embryos at the eight-cell embryo (60 vs $44 \%$ ), morula (45 vs $36 \%$ ), and blastocyst (38 vs $23 \%$ ) stages (Fig. 1). About 40\% IVF embryos developed to blastocysts as usual, in our facility. Note that the autologous, allogeneic, and IVF embryos were produced at the same OPU session, and the conditions for the three groups were kept as similar as possible for the procedures and assays described in this paper.

We also observed a difference in pregnancy and delivery rates between these two groups. Thirteen blastocysts derived from autologous SCNT and eighteen blastocysts derived from allogeneic SCNT were transferred into thirteen and eighteen pseudopregnant recipients respectively. The pregnancy rates at Day 90

Table 1 In vitro development of autologous and allogeneic somatic nuclear transfer bovine embryos reconstructed with cumulus cells.

\begin{tabular}{|c|c|c|c|c|c|c|c|c|c|c|}
\hline SCNT type & Oocyte & $\begin{array}{l}\text { No. of } \\
\text { replicates }\end{array}$ & $\begin{array}{c}\text { Oocyte } \\
\text { maturation } \\
(\%)\end{array}$ & КСC & $\begin{array}{c}\text { Fused } \\
(\%)^{\mathrm{a}}\end{array}$ & $\begin{array}{c}\text { Cultured } \\
(\%)\end{array}$ & $\begin{array}{l}\text { Cleaved } \\
(\%)^{b}\end{array}$ & $\begin{array}{c}\text { Eight-cell } \\
(\%)\end{array}$ & $\begin{array}{c}\text { Morula } \\
\quad(\%)\end{array}$ & $\begin{array}{c}\text { Blastocysts } \\
(\%)^{\mathrm{b}}\end{array}$ \\
\hline Autologous & 310 & 21 & $253(82)$ & 218 & $147(67)$ & $119(81)$ & $84(71)$ & $71(60)^{\mathrm{C}}$ & $54(45)^{\mathrm{C}}$ & $45(38)^{\mathrm{C}}$ \\
\hline Allogeneic & 1357 & 21 & $1100(81)$ & 906 & $569(63)$ & $450(79)$ & $300(67)$ & $198(44)^{d}$ & $162(36)^{d}$ & $105(23)^{d}$ \\
\hline
\end{tabular}

Listed are number of oocytes/embryos studied with the percentage in parentheses. KCC, karyoplast-cytoplast complexes. ${ }^{\text {c,d }}$ Values within columns with different superscript letters $c$, d differ with statistical significance $(P<0.05)$.

a Percentage based on number of KCCs used for fusion. ${ }^{b}$ Percentage based on number of surviving reconstructed embryos activated and cultured following KCC fusion. 


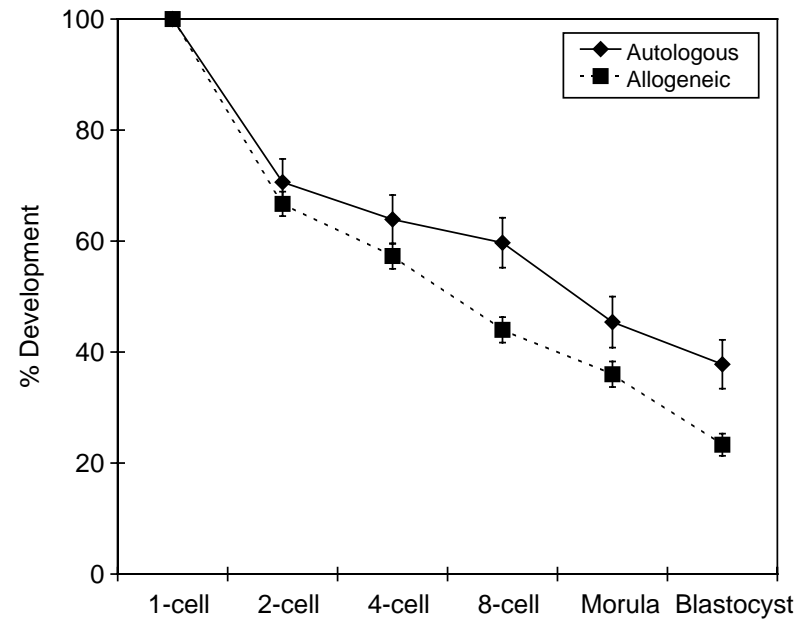

Figure 1 Developmental competence of autologous SCNT and allogeneic SCNT embryos. The percentage of surviving bovine embryos in each stage compared with the total number of reconstructed embryos cultured following fusion and activation of the KCCs in each group are plotted. The data represent 'mean \pm S.E.M'.

of gestation were 38.5 and $22.2 \%$ for autologous and allogeneic respectively. Three out of the thirteen recipients in the autologous SCNT group carried their fetuses to term $(23.1 \%)$, whereas only one calf was born in the allogeneic SCNT group (5.6\%; Table 2). There was no apparent defect or abnormality noted in any of these four cloned calves, and as expected, all were females.

\section{Microsatellite determination of origin of cloned calves}

Microsatellite profiles determined by the nine markers recommended by the ISAG showed exactly the same pattern for each of the cloned calves, its original bovine donor, and the donor cells used for initial cloning. In contrast, most of the microsatellites between the cloned calves and their foster mothers, as well as randomly selected Chinese Yellow Cattle were very different. This data confirmed that the genomes of these cloned calves evidently originate from the donor cells.

\section{mtDNA D-loop sequence homology comparison of cloned calves}

An mtDNA fragment, approximately $1.1 \mathrm{~kb}$, which includes a complete D-loop sequence, could be amplified from all the samples. Sequence homology comparisons for

Table 2 In vivo development of autologous and allogeneic somatic nuclear transfer bovine embryos.

\begin{tabular}{lcccc}
\hline NT type & $\begin{array}{c}\text { No. of } \\
\text { transferred } \\
\text { blastocysts }\end{array}$ & $\begin{array}{c}\text { No. of } \\
\text { recipients }\end{array}$ & $\begin{array}{c}\text { Pregnancy } \\
\text { rates at day } \\
\mathbf{9 0}(\%)\end{array}$ & $\begin{array}{c}\text { Newborn } \\
\text { rates }(\%)\end{array}$ \\
\hline Autologous & 13 & 13 & $5 / 13(38.5)$ & $3 / 13(23.1)$ \\
Allogeneic & 18 & 18 & $4 / 18(22.2)$ & $1 / 18(5.6)$ \\
Total & 31 & 31 & $9 / 31(29.0)$ & $4 / 31(12.9)$ \\
\hline
\end{tabular}

three autologous cloned calves showed that the mtDNA D-loop sequences were identical to their respective donor cells and oocytes from the donor, but different from their foster mothers; not surprisingly, the mtDNA D-loop sequences of allogeneic cloned bovines were different from those of the donor cells and their foster mothers.

\section{Histone H3-K9 methylation}

The patterns of distribution and intensity of dimethylated lysine 9 of histone H3 (H3-dimethK9) parallel closely with that of overall DNA methylation (Santos et al. 2003). In this study, the methylation profile of $\mathrm{H} 3-\mathrm{K} 9$ at blastocyst stage was determined to investigate the differences in epigenetic reprogramming in embryos derived from autologous SCNT, allogeneic SCNT, and IVF as normal control. Histone H3-K9 methylation analysis showed that the patterns of the cloned embryos derived from autologous SCNT resemble more closely with the H3-K9 profile from the control (IVF) embryos than the allogeneic SCNT (Table 3; Fig. 2). Eighty-one percent (21/26) of the control embryos (IVF) and fiftythree percent (9/17) of the autologous SCNT embryos successfully established epigenetic asymmetry with the trophectoderm showing lighter $\mathrm{H} 3-\mathrm{K} 9$ staining than that of the ICM. On the other hand, only $9 \%(1 / 11)$ of the embryos derived from allogeneic SCNT successfully established this asymmetry. The proportion of the IVF embryos displaying the apparently correct histone methylation pattern $(81 \%)$ was not significantly different compared with in vivo developed embryos $(7 / 9 ; 78 \%$; $P$ value of chi-squared test was 1 ). The difference in the successful establishment of epigenetic asymmetry between the embryos derived from autologous SCNT and IVF was not significant ( $P$ value was 0.09), whereas differences for autologous SCNT and allogeneic SCNT, or IVF and allogeneic SCNT, were significant ( $P$ values were $<0.001$ and $<0.05$ respectively).

\section{Discussion}

Most previous studies of nuclear transfer depended on large numbers of oocytes that were derived from the

Table 3 Comparison of $\mathrm{H} 3-\mathrm{K} 9$ methylation status in in vitro fertilization (IVF), autologous somatic cell nuclear transfer (SCNT), and allogeneic SCNT bovine blastocysts.

\begin{tabular}{lccc}
\hline & & \multicolumn{2}{c}{ H3-K9 methylation status } \\
\cline { 3 - 4 } Embryo types & N & Abnormal $(\%)$ & Normal $(\%)$ \\
\hline IVF blastocyst & 26 & $5(19.2)$ & $21(80.8)^{\mathrm{a}}$ \\
$\begin{array}{l}\text { Autologous SCNT } \\
\text { blastocysts }\end{array}$ & 17 & $8(47.1)$ & $9(52.9)^{\mathrm{a}}$ \\
$\begin{array}{l}\text { Allogeneic SCNT } \\
\text { blastocysts }\end{array}$ & 11 & $10(90.9)$ & $1(9.1)^{\mathrm{b}}$ \\
\hline
\end{tabular}

${ }^{a, b}$ Values in columns with different superscripts differ significantly $(P<0.05)$ based on Fisher's exact test. 

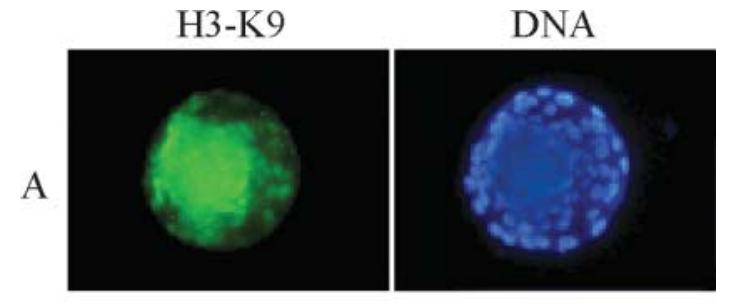

B
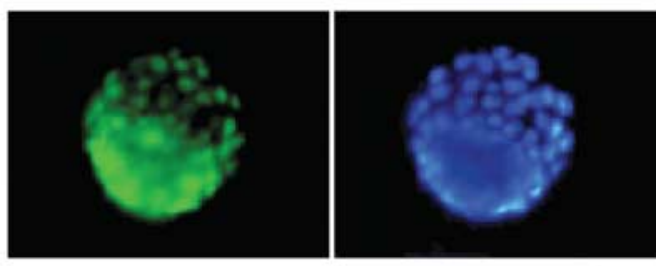

$\mathrm{C}$
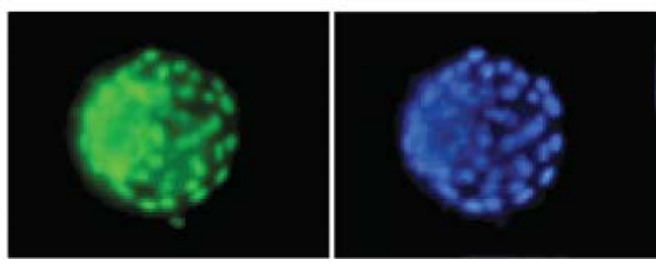

Figure 2 Epigenetic profiles of autologous SCNT, allogeneic SCNT, and IVF embryos. The bovine embryos were double stained for histone H3-K9 methylation (green) and DNA (blue, stained with DAPI to identify the nuclear compartment). The left column shows representative images of the anti-histone H3-dimethylK9 (H3-K9) immunofluorescence from IVF embryos (A, $n=26)$, autologous SCNT embryos (B, $n=17)$, and allogeneic SCNT embryos $(C, n=11)$ respectively. Blastocysts from IVF (A) and autologous SCNT treatments (B) showed hypomethylated trophectoderm and hypermethylated ICM, whereas allogeneneic SCNT blastocysts (C) had a more homogeneous pattern between trophectoderm and ICM.

ovaries of slaughtered cows, thus the genetic background of these oocytes are usually unknown. In this study, all oocytes used were recovered by OPU, which allowed us to keep track of the genetic origin of the oocytes, in addition to that of the donor cells, for a more valid comparison between the effect of autologous SCNT and allogeneic SCNT. Furthermore, in view of the important interrelationship between the nucleus and cytoplasm in embryo development, we are able to preserve the molecular and genetic context of these two compartments in the case of cloned embryos from autologous SCNT.

Mammalian preimplantation embryos rely mainly on maternal RNA and proteins for their development until embryonic genome activation (EGA) when a large number of genes required for further development are activated by the newly formed embryo (Zeng et al. 2004, Zeng \& Schultz 2005). The embryonic transcripts become essential for development thereafter because in the absence of these transcripts, embryos cannot cleave beyond the 9 - to 16 -cell stages in cattle (Memili \& First 1998, 1999). Our results demonstrated that embryos derived from autologous SCNT have a significantly higher developmental competence than those from allogeneic SCNT, especially at the preimplantation stages of eight-cell, morula, and blastocyst. Interestingly, the differences in developmental competency between the autologous and the allogeneic groups beyond the eight-cell stage coincide with the timing of the 'major gene activation' (Memili \& First 1999, Brunet-Simon et al. 2001). Thus, as more embryos in the autologous SCNT group developed beyond this 'major gene activation' stage, these embryos may have a betterpreserved mechanism for EGA, its regulation, and the resulting early embryonic development than those of the allogeneic SCNT embryos.

Previous studies show that the majority of cloned embryos dies throughout gestation, with only a small proportion reaching live birth (often $<4 \%$ ) (Wilmut et al. 2002, Hochedlinger \& Jaenisch 2003). In our study, the differences for the rates of pregnancy and live-born calves between the autologous SCNT and the allogeneic SCNT groups may reflect differences in blastocyst development prior to the embryo transfer, and suggest that the autologous SCNT preimplantation embryos may have a more appropriate microenvironment for further peri- and postimplantation development of the cloned embryos.

DNA methylation and chromatin errors are thought to contribute significantly to the low efficiency of somatic nuclear transfer (Kang et al. 2001). A recent study using the histone deacetylase inhibitor TSA to enhance the pool of acetylated histones (and associated DNA demethylation) indicated that this treatment apparently increased cloning efficiency in mouse, again suggesting the importance of these epigenetic factors in the development of clone embryos (Kishigami et al. 2006). Using antibodies to 5-methyl-cytosine and to the methylated and acetylated modifications of lysine 9 of histone H3, Santos et al. (2002, 2003) and Dean et al. (2001) characterized epigenetic profiles of preimplantation embryo chromatin. Accumulating evidence suggests that epigenetic reprogramming is severely defective in the cloned embryos from SCNT (Dean et al. 2001, Kang et al. 2001). At the blastocyst stage in both mouse and bovine, the inner cell mass (ICM), which gives rise to adult tissues, is normally hypermethylated, whereas trophectoderm (which gives rise to mostly placental tissues) is not (Dean et al. 2001, Santos et al. 2003). Therefore, we used the epigenetic asymmetry between ICM and trophectoderm as a reference to determine the proportion of embryos that have successfully achieved epigenetic reprogramming. Embryos that did not exhibit asymmetry had hypermethylated trophectoderm. Chromatin hypermethylation is associated with repression of transcription and gene silencing (Bird \& Wolffe 1999, Rideout et al. 2001). Our results of the $\mathrm{H} 3-\mathrm{K} 9$ stain intensity showed that most of the control embryos (IVF) and autologous SCNT embryos established the epigenetic asymmetry successfully. However, only 1 out of the 11 allogeneic SCNT embryos achieved the epigenetic asymmetry. Thus, autologous SCNT may 
decrease deficient epigenetic reprogramming during clone preimplantation development, which in turn decreases the occurrence of placental abnormalities associated with inappropriately repressed gene expression in the SCNT embryos.

Nuclear-cytoplasmic interactions are generally required for the faithful reprogramming that ensures the proper activation of genes during reconstructed embryonic development. Studies have shown different cloning efficacies for the production of viable and phenotypically normal offspring when using different combinations of nuclear donor cells and recipient oocyte cytoplasm in SCNT embryos (Du et al. 2002). Hiendleder et al. (2004) reported that recipient cytoplasm obtained from different bovine breeds could affect the in utero development, phenotype, and cellular metabolism of bovine nuclear transfer fetuses and this may be directly related to complex oocyte cytoplasmdependent epigenetic modifications. This is consistent with our finding that cloned embryos resulting from autologous SCNT have higher developmental potential than that of the allogeneic cytoplasm, probably due to a higher level of compatible factors contained in the autologous embryo cytoplasm that are crucial for nuclear reprogramming (Du et al. 2002).

There are a few other potential uses for and advantages of autologous SCNT, besides improvement of bovine cloning, which may extend the utility of the technique. First, this procedure can be applied to virtually all mammalian systems. Although the described experiments used the nuclei of female somatic cells as the donors for autologous SCNT, nuclei from male somatic cells can also be employed as donors when using enucleated recipient oocytes from the same maternal lineage. Since mitochondrial DNA are inherited maternally, once an oocyte from the maternal lineage is obtained, somatic cells from any progeny are adequate for 'near-autologous' SCNT. Mammalian mitochondrial components are encoded by both the mitochondrial and the nuclear DNA, requiring extensive nuclear-mitochondrial interactions for appropriate organelle function. Results of inter-species SCNTs suggested that evolutionarily more closely related species experience fewer problems with nuclear-mitochondrial compatibility (Rideout et al. 2001). A mitochondrial heteroplasmy study also showed that injection of foreign somatic cytoplasm or mitochondria affected parthenogenetic development of murine oocytes (Takeda et al. 2005). In the case of autologous cloned embryos, homoplasmy is preserved, and therefore most nuclear-mitochondrial incompatibilities could be avoided since both the nucleus and mitochondria of the reconstructed embryos come from the same individual. Secondly, the autologous SCNT technique enables the production of 'true cloned' animals. Cloned animals developed by allogeneic SCNT often represent 'genomic copies' of the nuclear donor, rather than true clones of the original individuals. Allogeneic SCNT will lead to partial or complete modification of the mitochondrial background of an embryo, and this may not only affect the immediate developmental competence, but also irreversibly change the inheritance of mitochondrial genes from the maternal lineage. Nevertheless, this issue theoretically can be avoided in terms of autologous SCNT since all the cellular components and the genetic origins are identical to that of the original donor. This in turn can be beneficial to 'therapeutic cloning' (Hochedlinger \& Jaenisch 2003). Finally, SCNT may provide useful experimental models for studying interactions between the nucleus and the cytoplasm, in addition to epigenetic reprogramming models in cloned embryos.

\section{Acknowledgements}

This work is supported by Chinese National '863' High-Tech Program (Grant No. 2002AA206211) and Shanghai Pujiang Scholar Programme (Grant No. 06PJ14060). The authors declare that there is no conflict of interest that would prejudice the impartiality of this scientific work.

\section{References}

Baguisi A, Behboodi E, Melican DT, Pollock JS, Destrempes MM, Cammuso C, Williams JL, Nims SD, Porter CA, Midura P, et al. 1999 Production of goats by somatic cell nuclear transfer. Nature Biotechnology 17 456-461.

Bird AP \& Wolffe AP 1999 Methylation-induced repression - belts, braces, and chromatin. Cell 99 451-454.

Brunet-Simon A, Henrion G, Renard JP \& Duranthon V 2001 Onset of zygotic transcription and maternal transcript legacy in the rabbit embryo. Molecular Reproduction and Development 58 127-136.

Campbell KH, McWhir J, Ritchie WA \& Wilmut I 1996 Sheep cloned by nuclear transfer from a cultured cell line. Nature 380 64-66.

Chesne P, Adenot PG, Viglietta C, Baratte M, Boulanger L \& Renard JP 2002 Cloned rabbits produced by nuclear transfer from adult somatic cells. Nature Biotechnology 20 366-369.

Cibelli JB, Stice SL, Golueke PJ, Kane JJ, Jerry J, Blackwell C, Ponce de Leon FA \& Robl JM 1998 Cloned transgenic calves produced from nonquiescent fetal fibroblasts. Science 280 1256-1258.

Dean W, Santos F, Stojkovic M, Zakhartchenko V, Walter J, Wolf E \& Reik W 2001 Conservation of methylation reprogramming in mammalian development: aberrant reprogramming in cloned embryos. PNAS 98 13734-13738.

Dinnyes A, Dai Y, Jiang S \& Yang X 2000 High developmental rates of vitrified bovine oocytes following parthenogenetic activation, in vitro fertilization, and somatic cell nuclear transfer. Biology of Reproduction 63 513-518.

Du F, Sung LY, Tian XC \& Yang X 2002 Differential cytoplast requirement for embryonic and somatic cell nuclear transfer in cattle. Molecular Reproduction and Development 63 183-191.

Galli C, Lagutina I, Crotti G, Colleoni S, Turini P, Ponderato N, Duchi R \& Lazzari G 2003 Pregnancy: a cloned horse born to its dam twin. Nature 424635.

Hiendleder S, Prelle K, Bruggerhoff K, Reichenbach HD, Wenigerkind $H$, Bebbere D, Stojkovic M, Muller S, Brem G, Zakhartchenko V, et al. 2004 Nuclear-cytoplasmic interactions affect in utero developmental capacity, phenotype, and cellular metabolism of bovine nuclear transfer fetuses. Biology of Reproduction 70 1196-1205.

Hochedlinger K \& Jaenisch R 2003 Nuclear transplantation, embryonic stem cells, and the potential for cell therapy. New England Journal of Medicine 349 275-286. 
Huang SZ, Huang Y, Chen MJ, Zeng FY, Ren ZR \& Zeng YT 2001 Selection of in vitro produced, transgenic embryos by nested PCR for efficient production of transgenic goats. Theriogenology $\mathbf{5 6}$ 545-556.

Kang YK, Koo DB, Park JS, Choi YH, Chung AS, Lee KK \& Han YM 2001 Aberrant methylation of donor genome in cloned bovine embryos. Nature Genetics 28 173-177.

Kato Y, Tani T, Sotomaru Y, Kurokawa K, Kato J, Doguchi H, Yasue H \& Tsunoda Y 1998 Eight calves cloned from somatic cells of a single adult. Science 282 2095-2098.

Kishigami S, Mizutani E, Ohta H, Hikichi T, Thuan NV, Wakayama S, Bui HT \& Wakayama T 2006 Significant improvement of mouse cloning technique by treatment with trichostatin A after somatic nuclear transfer. Biochemical and Biophysical Research Communications 340 183-189.

Memili E \& First NL 1998 Developmental changes in RNA polymerase II in bovine oocytes, early embryos, and effect of alpha-amanitin on embryo development. Molecular Reproduction and Development 51 381-389.

Memili E \& First NL 1999 Control of gene expression at the onset of bovine embryonic development. Biology of Reproduction 61 1198-1207.

Park SH, Shin MR \& Kim NH 2004 Bovine oocyte cytoplasm supports nuclear remodeling but not reprogramming of murine fibroblast cells. Molecular Reproduction and Development 68 $25-34$.

Polejaeva IA, Chen SH, Vaught TD, Page RL, Mullins J, Ball S, Dai Y, Boone J, Walker S, Ayares DL, et al. 2000 Cloned pigs produced by nuclear transfer from adult somatic cells. Nature 407 86-90.

Rideout WM III, Eggan K \& Jaenisch R 2001 Nuclear cloning and epigenetic reprogramming of the genome. Science 293 1093-1098.

Santos F, Hendrich B, Reik W \& Dean W 2002 Dynamic reprogramming of DNA methylation in the early mouse embryo. Developmental Biology 241 172-182.

Santos F, Zakhartchenko V, Stojkovic M, Peters A, Jenuwein T, Wolf E, Reik W \& Dean W 2003 Epigenetic marking correlates with developmental potential in cloned bovine preimplantation embryos. Current Biology 13 1116-1121.

Shin T, Kraemer D, Pryor J, Liu L, Rugila J, Howe L, Buck S, Murphy K, Lyons L \& Westhusin M 2002 A cat cloned by nuclear transplantation. Nature 415859.

Takeda K, Tasai M, Iwamoto M, Onishi A, Tagami T, Nirasawa K, Hanada H \& Pinkert CA 2005 Microinjection of cytoplasm or mitochondria derived from somatic cells affects parthenogenetic development of murine oocytes. Biology of Reproduction $\mathbf{7 2}$ 1397-1404.

Wakayama T \& Yanagimachi R 1999 Cloning of male mice from adult tail-tip cells. Nature Genetics 22 127-128.

Wakayama T, Perry AC, Zuccotti M, Johnson KR \& Yanagimachi R 1998 Full-term development of mice from enucleated oocytes injected with cumulus cell nuclei. Nature 394 369-374.

Wakayama T, Rodriguez I, Perry AC, Yanagimachi R \& Mombaerts P 1999 Mice cloned from embryonic stem cells. PNAS $\mathbf{9 6}$ 14984-14989.

Wilmut I, Schnieke AE, McWhir J, Kind AJ \& Campbell KH 1997 Viable offspring derived from fetal and adult mammalian cells. Nature 385 810-813.

Wilmut I, Beaujean N, de Sousa PA, Dinnyes A, King TJ, Paterson LA, Wells DN \& Young LE 2002 Somatic cell nuclear transfer. Nature 419 583-586.

Woods GL, White KL, Vanderwall DK, Li GP, Aston KI, Bunch TD, Meerdo LN \& Pate BJ 2003 A mule cloned from fetal cells by nuclear transfer. Science 3011063.

Yang XY, Li H, Huang WY, Huang SZ \& Zeng YT 2005a Comparison of two different schemes of once-weekly ovum pick up in dairy Heifers. Asian-Austrilasian Journal of Animal Science 18 314-319.

Yang XY, Zhao JG, Li HW, Li H, Liu HF, Huang SZ \& Zeng YT 2005b Improving in vitro development of cloned bovine embryos with hybrid (Holstein-Chinese Yellow) recipient oocytes recovered by ovum pick up. Theriogenology 64 1263-1272.

Zeng F \& Schultz RM 2005 RNA transcript profiling during zygotic gene activation in the preimplantation mouse embryo. Developmental Biology 283 40-57.

Zeng F, Baldwin DA \& Schultz RM 2004 Transcript profiling during preimplantation mouse development. Developmental Biology 272 483-496.

Zhou Q, Renard JP, Le Friec G, Brochard V, Beaujean N, Cherifi Y, Fraichard A \& Cozzi J 2003 Generation of fertile cloned rats by regulating oocyte activation. Science $\mathbf{3 0 2} 1179$.

Received 25 January 2006

First decision 20 February 2006

Revised manuscript received 23 April 2006

Accepted 13 July 2006 